$11-2007$

\title{
Pregnancy outcome in primiparae of advanced maternal age
}

Ilse Delbaere

Hans Verstraelen

Sylvie Goetgeluk

Guy Martens

Guy De Backer

See next page for additional authors

Follow this and additional works at: https://ecommons.aku.edu/eastafrica_fhs_mc_obstet_gynaecol

Part of the Endocrinology, Diabetes, and Metabolism Commons, and the Obstetrics and Gynecology Commons 


\section{Authors}

Ilse Delbaere, Hans Verstraelen, Sylvie Goetgeluk, Guy Martens, Guy De Backer, and Marleen Temmerman 


\title{
Pregnancy outcome in primiparae of advanced maternal age
}

\author{
Ilse Delbaere ${ }^{\mathrm{a}, *}$, Hans Verstraelen ${ }^{\mathrm{a}}$, Sylvie Goetgeluk ${ }^{\mathrm{b}}$, Guy Martens ${ }^{\mathrm{c}}$, \\ Guy De Backer ${ }^{\mathrm{d}}$, Marleen Temmerman ${ }^{\mathrm{a}}$ \\ ${ }^{a}$ Department of Obstetrics and Gynaecology, Faculty of Medicine and Health Sciences, \\ Ghent University Hospital, De Pintelaan 185, 9000 Ghent, Belgium \\ ${ }^{\mathrm{b}}$ Department of Applied Mathematics and Informatics, Ghent University, Belgium \\ ${ }^{\mathrm{c}}$ Study Centre for Perinatal Epidemiology, Brussels, Belgium \\ ${ }^{\mathrm{d}}$ Department of Public Health, Ghent University, Belgium
}

Received 9 March 2006; received in revised form 14 September 2006; accepted 24 October 2006

\begin{abstract}
Objective: To investigate the impact of maternal age on singleton pregnancy outcome, taking into account intermediate and confounding factors.

Study design: In this population-based retrospective cohort study, perinatal data of primiparous women aged 35 years or more $(n=2970)$, giving birth to a singleton child of at least $500 \mathrm{~g}$, were compared to data of primiparous women aged 25-29 years old $(n=23,921)$. Univariate analysis was used to assess the effect of maternal age on pregnancy outcomes. The effects of intermediate (hypertension, diabetes and assisted conception) and confounding factors (level of education) were assessed through multivariable logistic regression analysis.

Results: Older maternal age correlated, independently of confounding and intermediate factors, with very preterm birth (gestational age $<32$ weeks) [adjusted odds ratio (AOR) 1.51, 95\% confidence intervals (CI) 1.04-2.19], low birth weight (birth weight $<2500$ g) (AOR 1.69, 95\% CI 1.47-1.94) and perinatal death (AOR 1.68, 95\% CI 1.06-2.65).

Conclusion: Maternal age is an important and independent risk factor for adverse pregnancy outcome.

(C) 2006 Elsevier Ireland Ltd. All rights reserved.
\end{abstract}

Keywords: Pregnancy outcome; Advanced maternal age; Hypertension; Diabetes; ART

\section{Introduction}

Maternal age has been repeatedly scrutinized as a putative risk factor for adverse pregnancy outcome [1-7]. Though the preponderance of these studies tend to indicate that women of advanced ( $\geq 35$ years) and high ( $\geq 40$ years) maternal age do incur a significantly increased risk of obstetric complications and interventions, it has also been argued that current evidence on the association between maternal age and perinatal outcome remains largely clouded by age-related confounding factors [5,8-10]. Type II diabetes and hypertension show an incremental increase with advancing maternal age and therefore act as mediating variables on the pathway between age and pregnancy

\footnotetext{
* Corresponding author. Tel.: +32 924048 53; fax: +32 92403831 .

E-mail address: Ilse.Delbaere@UGent.be (I. Delbaere).
}

outcome [5]. In this manner, it remains unclear how much maternal age itself contributes to poor pregnancy outcome rather than age-related co-morbidity. This perspective encouraged us to investigate the effect of confounding (level of education) and mediating variables (hypertension, diabetes, mode of conception) in the relationship between maternal age and pregnancy outcome.

\section{Materials and methods}

Data were obtained from the existing computer files of a regional population-based perinatal database, the Flemish Study Centre for Perinatal Epidemiology (SPE) [11]. For each newborn of at least $500 \mathrm{~g}$, an official and coded perinatal form was completed (most often by the midwife) and sent to the SPE, where all data were controlled by an 
error detection program and feedback was provided [12]. A qualitative assessment of SPE-data showed that there was less than five percent discrepancy between electronic data and data from medical files. Data concerning education of the mother were obtained through linkage of the medical birth certificates of the SPE with official birth declarations.

All primiparous women aged 35 years or more and all primiparous women between 25 and 29 years old, who delivered a singleton baby with a birth weight of at least $500 \mathrm{~g}$ between January 1, 2002 and December 31, 2003 were included in this cohort study. The control group was defined as the age-group 25-29 years old, because this was the category with the largest number of births in Flanders (the mean age at first delivery in Flanders is 27.7 years). Because of the intrinsic risks of multiple pregnancies, this study was restricted to singleton pregnancies. The following variables were analysed: maternal age as independent variable, mode of conception, hypertension in pregnancy and diabetes in pregnancy as intermediate variables, level of education as confounding variable, induction of labour, epidural anaesthesia, mode of delivery, maternal mortality, position of the child, gestational age, birth weight, congenital malformation, intubation, transfer to a neonatal unit and perinatal mortality as dependent variables.

The protocol of this study was approved by the institutional review board of the University Hospital, Ghent.

Maternal age was defined as the age at the time of delivery. The age of 35 or older was considered as advanced maternal age. Mode of conception was registered as 'spontaneous', after 'artificial induction of ovulation' (AIO) or through 'assisted reproductive techniques' (ART). In the multivariate analysis, we adjusted for the differential effects of AIO and ART on the outcomes assessed. For the variables 'hypertensive disorders during pregnancy' and 'diabetes during pregnancy', the data did not allow to make a distinction between chronic or pregnancy induced hypertension, nor between the different types of diabetes. Maternal education was handled as an indicator for socio-economic status. Though there are numerous parameters to assess socioeconomic status, education has consistently been found as the most valid indicator for SES [13]. Education level was classified into two categories: women who went to school until the age of 15 years or less as the lower educated category, the other women were considered as the higher educated category. Delivery before 37,32 or 28 completed weeks of gestation was defined as preterm birth, very preterm birth and extreme preterm birth, respectively. Macrosomia was defined as birth weight exceeding $4000 \mathrm{~g}$. Birth weights lower than 2500,1500 or $1000 \mathrm{~g}$ were defined as low birth weight, very low birth weight and extreme low birth weight, respectively. In the variable 'birth weight', no distinction was made between preterm and small for gestational age (SGA) children. SGA was defined as a birth-weight-for-gestational-age below the 10th percentile according to customized birth weight for gestational age-curves for this population, accounting for sex of the child.

Univariate analysis $\left(\chi^{2}\right.$-test $)$ was used to examine the effect of maternal age on pregnancy outcome, crude odds ratios (OR) and 95\% confidence intervals (CI) were obtained. To examine the role of intermediate factors (hypertensive disorders in pregnancy, diabetes in pregnancy and mode of conception), or confounding factors (level of education) in the relationship between maternal age and pregnancy outcome, logistic regression analysis (enter mode) was performed. Thus, adjusted odds ratios (AOR) and $95 \%$ confidence intervals were calculated for maternal age and potential intermediate or confounding factors in relation to pregnancy outcome. Levene's test was performed to check for unequal distributions in birth weight between older and younger mothers. Since the Levene's test showed an unequal distribution in the birth weights of children of older versus younger mothers, the Welch's $t$-test was performed. This test takes unequal variances into account and resulted in a $P$-value $<0.001$. The box plots for birth weights show a more or less equal distribution, but with many outliers in both age-groups. Because of these outliers, a Mann-Whitney $U$-test comparing the medians was performed, also resulting in a $P$-value $<0.001$.

Goodness-of-fit has been calculated for each model, $P$ values range from 0.339 to 0.973 , proving the logistic regression models are adequate.

Possible interaction effects were explored between intermediate/confounding variables and maternal age. All analyses were performed using the statistical package SPSS 12.0 (SPSS Inc., Chicago, IL).

\section{Results}

In 2002-2003, the SPE registered 118,094 deliveries of neonates $\geq 500 \mathrm{~g}$. Out of these, 2970 (2.5\%) were singletons in primiparae $\geq 35$ years and 23,921 (20.2\%) singletons in

Table 1

Maternal characteristics by age

\begin{tabular}{lrr}
\hline & Age 25-29 years $(n=23,921)$ & Age $\geq 35$ years $(n=2970)$ \\
\hline Assisted conception & $954(4.0 \%)$ & $398(13.4 \%)$ \\
$\quad$ Artificial induction of ovulation & $570(2.4 \%)$ & $125(4.5 \%)$ \\
Assisted reproductive technology & $383(1.6 \%)$ & $273(9.2 \%)$ \\
Hypertension during pregnancy & $1586(6.6 \%)$ & $<0.001$ \\
Diabetes during pregnancy & $270(1.1 \%)$ & $258(8.7 \%)$ \\
Lower education (until age of 15 years) & $1476(6.2 \%)$ & $74(2.5 \%)$ \\
\hline
\end{tabular}


Table 2

Outcome according to maternal age, accounting for hypertension during pregnancy, diabetes during pregnancy, mode of conception and level of education (crude OR, adjusted OR and 95\% confidence intervals) for 2002-2003

\begin{tabular}{|c|c|c|c|c|c|c|}
\hline \multirow[b]{2}{*}{ Induction of delivery } & \multirow{2}{*}{$\begin{array}{l}\text { Age } 25-29 \text { years } \\
(n=23,921) \\
\% \\
29.1\end{array}$} & \multirow{2}{*}{$\begin{array}{l}\text { Age } \geq 35 \text { years } \\
(n=2970) \\
\% \\
30.0\end{array}$} & \multicolumn{2}{|c|}{$\begin{array}{l}\text { Crude OR and } 95 \% \mathrm{CI} \text { or } \\
P \text {-value }\end{array}$} & \multicolumn{2}{|c|}{$\begin{array}{l}\text { Adjusted OR and } 95 \% \text { CI } \\
\text { or Adjusted } P \text {-value }^{\text {a }}\end{array}$} \\
\hline & & & 1.05 & $(0.96-1.14)$ & 1.01 & $(0.93-1.10)$ \\
\hline Epidural anesthesia & 72.0 & 74.4 & 1.12 & $(1.03-1.23)$ & 1.11 & $(1.02-1.21)$ \\
\hline \multicolumn{7}{|l|}{ Duration of gestation } \\
\hline Mean gestational age in days $( \pm$ S.D. $)$ & $272.5( \pm 12.4)$ & $271.8( \pm 14.8)$ & & $<0.01$ & & 0.363 \\
\hline Preterm birth ( $<37$ weeks $)$ & 7.1 & 8.8 & 1.26 & $(1.10-1.44)$ & 1.14 & $(0.98-1.33)$ \\
\hline Very preterm birth $(<32$ weeks $)$ & 0.8 & 1.3 & 1.76 & $(1.24-2.49)$ & 1.51 & $(1.04-2.19)$ \\
\hline Extreme preterm birth ( $<28$ weeks) & 0.2 & 0.6 & 2.64 & $(1.53-4.58)$ & 1.97 & $(1.06-3.67)$ \\
\hline \multicolumn{7}{|l|}{ Mode of delivery } \\
\hline Vaginal delivery & 62.4 & 48.0 & 0.56 & $(0.52-0.60)$ & 0.57 & $(0.53-0.62)$ \\
\hline Forceps or vacuum & 19.0 & 21.8 & 1.19 & $(1.08-1.30)$ & 1.19 & $(1.08-1.30)$ \\
\hline Cesarean section & 18.6 & 30.2 & 1.89 & $(1.73-2.05)$ & 1.78 & $(1.62-1.95)$ \\
\hline Non-vertex presentation & 6.3 & 8.2 & 1.34 & $(1.16-1.54)$ & 1.35 & $(1.17-1.55)$ \\
\hline $\begin{array}{l}\text { Small for gestational age } \\
\quad \text { (birth weight }<10 \text { th percentile) }\end{array}$ & 7.9 & 12.0 & 1.59 & $(1.41-1.79)$ & 1.53 & $(1.39-1.77)$ \\
\hline \multicolumn{7}{|l|}{ Birth weight } \\
\hline Mean birth weight ( \pm S.D.) & $3282.4( \pm 515.0)$ & $3203.7( \pm 588.6)$ & & $<0.001$ & & $<0.001$ \\
\hline Low birth weight $(<2500 \mathrm{~g})$ & 5.6 & 9.7 & 1.80 & $(1.58-2.06)$ & 1.69 & $(1.47-1.94)$ \\
\hline Very low birth weight $(<1500 \mathrm{~g})$ & 0.8 & 1.6 & 1.93 & $(1.40-2.65)$ & 1.62 & $(1.15-2.28)$ \\
\hline Extreme low birth weight $(<1000 \mathrm{~g})$ & 0.3 & 0.8 & 2.70 & $(1.70-4.29)$ & 2.14 & $(1.29,3.56)$ \\
\hline Macrosomia $(>4000 \mathrm{~g})$ & 6.6 & 5.9 & 0.89 & $(0.76-1.05)$ & 0.89 & $(0.76-1.04)$ \\
\hline Congenital malformation & 1.6 & 1.8 & 1.12 & $(0.84-1.49)$ & 1.06 & $(0.79-1.43)$ \\
\hline Intubation & 0.7 & 1.4 & 1.95 & $(1.38-2.74)$ & 1.86 & $(1.32-2.62)$ \\
\hline Transfer to neonatal unit & 17.3 & 23.2 & 1.44 & $(1.32-1.58)$ & 1.34 & $(1.22-1.48)$ \\
\hline Perinatal death $(\%)$ & 4.8 & 9.4 & 1.95 & $(1.29-2.96)$ & 1.68 & $(1.06-2.65)$ \\
\hline Fetal death & 0.4 & 0.7 & 2.04 & $(1.28-3.27)$ & 1.69 & $(0.99-2.87)$ \\
\hline Early neonatal death & 0.1 & 0.2 & 1.67 & $(0.69-4.02)$ & 1.71 & $(0.70-4.20)$ \\
\hline Maternal mortality (\%o) & 0.1 & 0.3 & 2.69 & $(0.28-25.83)$ & 2.20 & $(0.23-21.25)$ \\
\hline
\end{tabular}

a Adjusted for mode of conception, hypertension during pregnancy, diabetes during pregnancy and level of education.

women between 25 and 29 years. Patient characteristics of both age-groups were summarized in Table 1. In older women, pregnancy was more likely to be obtained by assisted conception $(P<0.001)$. Compared with younger primiparae, older women were more likely to suffer from risk factors in pregnancy, such as hypertension and diabetes $(P<0.001)$. Older primiparae enjoyed significantly more often higher education $(P<0.001)$.

Table 2 summarizes the effect of maternal age on adverse outcomes of pregnancy.

After adjusting for hypertension, diabetes, mode of conception and level of education, rates of most adverse outcomes remained significantly higher in older primiparae. In particular, we found increased rates of very preterm birth (AOR 1.51, 95\% CI 1.04-2.19), extreme preterm birth (AOR 1.97, 95\% CI 1.06-3.67), low birth weight (AOR 1.69, 95\% CI 1.47-1.94), very low birth weight (AOR 1.62, 95\% CI 1.15-2.28), extreme low birth weight (AOR 2.14, 95\% CI 1.29-3.56) and perinatal death (AOR 1.68, 95\% CI 1.06-2.65) in primiparae of advanced maternal age, after controlling for intermediate and confounding factors. There was a higher caesarean section rate in older primiparae (30.2\% versus $18.6 \%$, AOR 1.78 , 95\% CI 1.62-1.95). Congenital malformations were not more common in children of older primiparae, compared with children of the younger age-group (AOR 1.06, 95\% CI 0.79-1.43).

The effect of confounding and intermediate variables in the relation maternal age-outcome, are found in Table 3. Hypertension during pregnancy seemed to be an important intermediate factor in the relation maternal age-pregnancy outcome, especially for all categories of preterm birth and low birth weight. Low level of education had an important impact on most pregnancy outcome variables as well.

Interactions between maternal age and confounding/ intermediate variables were explored. For the outcome 'induction of delivery' we found a significant interaction between 'hypertension during pregnancy' and 'maternal age' and between 'diabetes during pregnancy' and 'maternal age'. In hypertensive women, the odds to have an induced delivery is 0.68 in older versus younger primiparae. In non-hypertensive women, the odds to have an induced delivery is 1.06 in older versus younger primiparae. In diabetic women, the odds to have an induced 
Table 3

Outcome of pregnancy in relation to maternal age: the effect of selected intermediate variables and confounders (adjusted OR and 95\% confidence intervals)

\begin{tabular}{|c|c|c|c|c|c|c|c|}
\hline \multirow[b]{3}{*}{ Induction of delivery } & \multirow{3}{*}{$\begin{array}{l}\text { Mode of conception } \\
P \text {-value } \\
\text { NS }\end{array}$} & \multicolumn{2}{|c|}{ Hypertension } & \multicolumn{2}{|c|}{ Diabetes } & \multicolumn{2}{|c|}{ Low education } \\
\hline & & \multicolumn{2}{|c|}{ Adjusted $\mathrm{OR}^{\mathrm{b}}$} & \multicolumn{2}{|c|}{ Adjusted $\mathrm{OR}^{\mathrm{c}}$} & \multicolumn{2}{|c|}{ Adjusted OR ${ }^{d}$} \\
\hline & & 3.16 & $(2.87-3.48)$ & 1.48 & $(1.18-1.84)$ & & NS \\
\hline Epidural anesthesia & NS & 1.51 & $(1.34-1.70)$ & 1.41 & $(1.07-1.84)$ & 1.15 & $(1.03-1.29)$ \\
\hline \multicolumn{8}{|l|}{ Duration of gestation } \\
\hline Gestational age in days & $P<0.01$ & & $P<0.001$ & & $P<0.001$ & & $P<0.001$ \\
\hline Preterm birth (<37 weeks) & $P<0.05$ & 3.32 & $(2.90-3.79)$ & 1.58 & $(1.12-2.22)$ & 1.34 & $(1.12-1.59)$ \\
\hline Very preterm birth (<32 weeks) & NS & 4.57 & $(3.30-6.32)$ & & NS & 2.50 & $(1.69-3.68)$ \\
\hline Extreme preterm birth $(<28$ weeks $)$ & NS & 4.36 & $(2.42-7.86)$ & & NS & 3.26 & $(1.72-6.19)$ \\
\hline \multicolumn{8}{|l|}{ Mode of delivery } \\
\hline Vaginal delivery & NS & 0.59 & $(0.53-0.65)$ & 0.60 & $(0.48-0.75)$ & 0.80 & $(0.73-0.89)$ \\
\hline Forceps or vacuum & NS & & NS & & NS & & NS \\
\hline Cesarean section & $P<0.001$ & 1.84 & $(1.64-2.05)$ & 1.92 & $(1.51-2.45)$ & 1.25 & $(1.11-1.40)$ \\
\hline Non-vertex presentation & NS & 0.69 & $(0.55-0.86)$ & & NS & & NS \\
\hline $\begin{array}{l}\text { Small for gestational age } \\
\quad \text { (birth weight }<10 \text { th percentile) }\end{array}$ & NS & 1.82 & $(1.58-2.11)$ & & NS & 1.34 & $(1.14-1.57)$ \\
\hline \multicolumn{8}{|l|}{ Birth weight } \\
\hline Mean birth weight & NS & & $P<0.001$ & & NS & & $P<0.001$ \\
\hline Low birth weight $(<2500 \mathrm{~g})$ & NS & 3.88 & $(3.40-4.45)$ & & NS & 1.61 & $(1.35-1.91)$ \\
\hline Very low birth weight $(<1500 \mathrm{~g})$ & NS & 6.35 & $(4.78-8.45)$ & & NS & 2.60 & $(1.82-3.73)$ \\
\hline Extreme low birth weight $(<1000 \mathrm{~g})$ & NS & 7.20 & $(4.59-11.28)$ & & NS & 2.97 & $(1.71-5.16)$ \\
\hline Macrosomia $(>4000 \mathrm{~g})$ & NS & 0.75 & $(0.61-0.93)$ & 1.83 & $(1.30-2.59)$ & & NS \\
\hline Congenital malformation & NS & & NS & & NS & 1.67 & $(1.22-2.29)$ \\
\hline Intubation & NS & 3.85 & $(2.77-5.34)$ & & NS & & NS \\
\hline Transfer to neonatal unit & NS & 2.31 & $(2.08-2.56)$ & 2.42 & $(1.92-3.04)$ & 1.33 & $(1.18-1.49)$ \\
\hline Perinatal death & NS & 1.80 & $(1.04-3.10)$ & & NS & 4.17 & $(2.74-6.35)$ \\
\hline Foetal death & NS & & NS & & NS & 4.00 & $(2.45-6.53)$ \\
\hline Early neonatal death & NS & & NS & & NS & 4.66 & $(2.08-10.48)$ \\
\hline
\end{tabular}

Above mentioned OR's and $P$ : values are obtained from the original multivariate analysis model.

a Adjusted for maternal age, hypertension, diabetes and education.

b Adjusted for maternal age, assisted conception, diabetes and education.

c Adjusted for maternal age, assisted conception, hypertension and education.

d Adjusted for maternal age, assisted conception, hypertension and diabetes.

delivery is 0.38 in older versus younger primiparae. In nondiabetic women, the odds to be induced is 1.06 in older versus younger women. The higher risk for induction of delivery in hypertensive and diabetic younger women can possibly be explained through the higher proportion of acute pre-eclamptic and type I diabetes patients in this population, compared to more chronic hypertensive disease and type II diabetes in older primiparae. No other clinically relevant interactions were found.

\section{Comment}

Even after adjusting for hypertension, diabetes, level of education and mode of conception, maternal age proved an independent risk factor for adverse pregnancy outcome.

This study was based on a large sample size and is one of the few population-based studies. In addition, it was possible to adjust for intermediate and confounding factors. Only a small number of previous studies corrected their data for mode of conception [4].
Limitations of our study include that data concerning gravidity, body mass index (BMI), smoking habits and other variables that may interact in the relation maternal agepregnancy outcome, were not available $[1,4,14-16]$. Furthermore, it is possible that there was a better diagnosis of complications in older women since they might be monitored more thoroughly [17]. Finally, in this database, women were known to be hypertensive during pregnancy or not. No distinction could be made between chronic hypertension and pre-eclampsia. It would be recommendable for birth registers to enter data that distinguish between new-onset complications and chronic diseases. Also, additional inventory of anthropometric variables (BMI, weight gain during pregnancy) are of interest to the study of pregnancy outcome.

In general, the results of our univariate analysis support the findings of earlier studies $[1,2,6,18,19]$. Assisted conception [20], caesarean section [4,5,17,21-25], preterm birth $[3,6,7,26]$, low birth weight $[2,10]$, intensive neonatal care $[17,19,27]$ and perinatal death $[4,6]$ were more common in primiparae of advanced maternal age. Surprisingly, the incidence of congenital malformations at birth was not significantly higher in older primiparous women. Other 
authors came to the same conclusion [3]. Ales et al. assigned this outcome to the intense screening of the older population, followed by interruption of pregnancy [8]. Thanks to screening, the incidence of congenital malformations and stillbirth have decreased firmly during the last decades [28].

As the incidence of maternal mortality is low in Flanders, we did not reach a significant difference in comparing maternal mortality rates in older to younger primiparae. The frequency of maternal mortality was nevertheless higher in older primiparae, as has been reported earlier [1,29].

Our data, as well as results of previous studies [1,2,5,6,27], show pregnancy complications to occur more frequently in women of advanced age. This observation has led to the hypothesis that adverse outcome in older primiparae was attributable to the higher incidence of complicated pregnancy in these women $[5,8-10]$. Our data show maternal age to be responsible for unfavourable outcomes even after controlling for pregnancy complications, such as hypertension and diabetes. The effect of low level of education or hypertension on pregnancy outcome can however not be denied. Our multivariate model shows that hypertensive women run threefold higher odds for preterm birth and three to four-fold higher odds to deliver a child of low birth weight. Since the risk to develop hypertension ascends with age, older mothers run a double jeopardy: the possibility to acquire hypertension and the risks inherent to maternal age.

Pregnancy and childbirth are increasingly "medicalised" events [30], especially in older primiparae. Conception in older primiparae is more likely a consequence of assisted reproduction, maternal age has an adverse impact on the gestational age and birth weight of the child and older mothers have higher risks to deliver by means of caesarean section. Hence, the trend to delayed childbearing is an increasingly important public health concern. Potential interventions to reduce adverse pregnancy outcome related to maternal age could include patient education: awareness of the special risks in pregnancy at older age is useful in younger women who tend to postpone motherhood. At the level of public authorities, also the design of a more familyfriendly environment may be helpful in the motivation of young couples to consider starting a family earlier.

\section{Acknowledgments}

We would like to thank all Flemish gynaecologists and midwives for their contribution in the SPE-registration. We also acknowledge the scientific committee of the SPE and the Flemish Ministry of Health for the access to their data, as well as Vanessa De Bolle and Sylvie Vermeren for their committed registration.

\section{References}

[1] Hansen JP. Older maternal age and pregnancy outcome: a review of literature. Obstet Gynecol Surv 1986;41(11):726-42.
[2] Gilbert WM, Nesbitt TS, Danielsen B. Childbearing beyond age 40: pregnancy outcome in 24032 cases. Obstet Gynecol 1999;93(1):9-14.

[3] Seoud MAF, Nassar AH, Usta IM, Melhem Z, Kazma A, Khalil AM. Impact of advanced maternal age on pregnancy outcome. Am J Perinatol 2002;19(1):1-7.

[4] Cleary-Goldman J, Malone FD, Vidaver J, Ball RH, Nyberg DA, Comstock $\mathrm{CH}$, et al. Impact of advanced maternal age on obstetric outcome. Obstet Gynecol 2005;105(5):983-90.

[5] van Katwijk C. Peeters LLH. Clinical aspects of pregnancy after the age of 35 years: a review of the literature. Hum Reprod Update 1998;4(2):185-94.

[6] Jacobsson BM, Ladfors LM, Milsom IM. Advanced maternal age and adverse perinatal outcome. Obstet Gynecol 2004;104(4): 727-33.

[7] Joseph KSM, Allen ACM, Dodds LP, Turner LAP, Scott HM, Liston RM. The perinatal effects of delayed childbearing. Obstet Gynecol 2005;105(6):1410-8.

[8] Ales KL, Druzin ML, Santini DL. Impact of advanced maternal age on the outcome of pregnancy. Surg Gynecol Obstet 1990;171: 209-16.

[9] Barton JR, Bergauer NK, Jacques DL, Coleman SK, Stanziano GJ, Sibai BM. Does advanced maternal age affect pregnancy outcome in women with mild hypertension remote from term? Am J Obstet Gynecol 1997;176(6):1236-40.

[10] Yuan W, Steffensen FH, Nielsen GL, Moller M, Olsen J, Sorensen HT. A population-based cohort study of birth and neonatal outcome in older primipara. Int J Gynaecol Obstet 2000;68(2):113-8.

[11] Vleugels A, Bekaert A. The Flemish Centre for the study of perinatal epidemiology and its registry. Qual Assur Health Care 1992;4(2):11524.

[12] Cammu H, Martens G, Ruyssinck G, Amy J-J. Outcome after elective labor induction in nulliparous women: a matched cohort study. Am J Obstet Gynecol 2002;186:240-4.

[13] Kramer MS, Seguin L, Lydon J, Goulet L. Socio-economic disparities in pregnancy outcome: why do the poor fare so poorly? Paediatr Perinat Epidemiol 2000;14(3):194-210.

[14] Scholz HS, Haas J, Petru E. Do primiparas aged 40 years or older carry an increased obstetric risk? Prev Med 1999;29(4):263-6.

[15] Andersen A-MN, Wohlfahrt J, Christens P, Olsen J, Melbye M. Maternal age and fetal loss: population based register linkage study. BMJ 2000;320:1708-12.

[16] Spellacy WN, Miller SJ, Winegar A. Pregnancy after 40 years of age. Obstet Gynecol 1986;68:452-4.

[17] Bell JS, Campbell DM, Graham WJ, Penney GC, Ryan M, Hall MH. Can obstetric complications explain the high levels of obstetric interventions and maternity service use among older women? Br J Obstet Gynaecol 2001;108:910-8.

[18] Ananth CV, Joseph KS, Smulian JC. Trends in twin neonatal mortality rates in the United States 1989 through 1999: influence of birth registration and obstetric intervention. Am J Obstet Gynecol 2004;190(5):1313-21.

[19] Prysak M, Lorenz RP, Kisly A. Pregnancy outcome in nulliparous women 35 years and older. Obstet Gynecol 1995;85(1):65-70.

[20] Pandian Z, Bhattacharya S, Templeton A. Review of unexplained infertility \& obstetric outcome: a 10 year review. Hum Reprod 2001;16(12):2593-7.

[21] Adashek JA, Peaceman AM, Lopezzeno JA, Minogue JP, Socol ML. Factors contributing to the increased cesarean birth-rate in older parturient women. Am J Obstet Gynecol 1993;169(4): 936-40.

[22] Dulitzki M, Soriano D, Schiff E, Chetrit A, Mashiach S, Seidman DS. Effect of very advanced maternal age on pregnancy outcome and rate of cesarean delivery. Obstet Gynecol 1998;92(6):935-9.

[23] Ecker JL, Chen KT, Cohen AP, Riley LE, Lieberman ES. Increased risk of cesarean delivery with advancing maternal age: indications and associated factors in nulliparous women. Am J Obstet Gynecol 2001;185(4):883-7. 
[24] Gareen IF, Morgenstern H, Greenland S, Gifford DS. Explaining the association of maternal age with cesarean delivery for nulliparous and parous women. J Clin Epidemiol 2003;56: 1100-10.

[25] Heffner LJ, Elkin E, Fretts RC. Impact of labor induction, gestational age, and maternal age on cesarean delivery rates. Obstet Gynecol 2003;102:287-93.

[26] Miller DA. Is advanced maternal age an independent risk factor for uteroplacental insufficiency? Am J Obstet Gynecol 2005;192(6): 1974-80.
[27] Bianco A, Stone J, Lynch L, Lapinski R, Berkowitz G, Berkowitz R. Pregnancy outcome at age 40 and older. Obstet Gynecol 1996;87 (6):917-22.

[28] Fretts RC, Usher RH. Causes of fetal death in women of advanced maternal age. Obstet Gynecol 1997;89(1):40-5.

[29] Temmerman M, Verstraelen H, Martens G, Bekaert A. Delayed childbearing and maternal mortality. Eur J Obstet Gynecol Reprod Biol 2004;114:19-22.

[30] Johanson R, Newburn M, Macfarlane A. Has the medicalisation of childbirth gone too far? BMJ 2002;324(7342):892-5. 